\title{
Analysis of engines life cost to control and improve yachts management and reliability
}

\author{
G. Radica, N. Račić \& J. Kasum \\ Faculty of Maritime Studies, Split, Croatia
}

\begin{abstract}
The economical and safe operation of a yacht depends on numerous factors, the most important of which include permanent operating reliability and availability of the complete equipment, from the main engine to the technical systems which are not in permanent use. A high level of availability depends on the quality of the maintenance. The maintenance strategy and proper engine investment analysis, integrated with the stock control and purchase orders, are undoubtedly the best solution. The computer support in the integrated maintenance system, combined with data transfer possibilities via powerful satellite communications, is the basis of a successful yacht management. Well organised maintenance planning and the spare parts control system provide a high level of the vessel's equipment reliability over the entire vessel's life time.
\end{abstract}

Keywords: diesel engine, engine investment analysis, life cost.

\section{Introduction}

At present, yacht owners and yacht builders have been intensively analysing and calculating the costs of yacht maintaining to increase efficiency and improve economical effects of the investment. Each engine has its own distinctive features, which raises the need of acquiring new insights into engines.

\section{Engine investment analysis}

Manufacturers of diesel engines have developed programs for analysing the economic investment effects and overall investment when selecting an engine (Radan [1]). A particular attention is paid to maintenance and proper engine operation. Access to the necessary data is available to enable comparison to other 
engines. The results of the analysis will clearly show the effect of fuel and maintenance in overall costs, e.g. in the case of an engine whose fuel consumption is $10 \%$ higher or whose lube oil is $100 \%$ higher, or in the case of an engine that requires considerably less overhaul time. All these factors affect the operating costs. The share of an engine's selling price may represent even less than $2 \%$ of total engine investment over its life cycle. The maintenance cost is the second largest cost following the fuel cost, so that the maintenance quality will eventually be related to the engine's durability. Due to quality maintenance, the overall economic index may be improved to a large extent. According to the manufacturers' guidelines, the life of diesel engines is expected to be around 20 years, with at least several major overhauls. The programs for Engine Investment Analysis (EIA), provided by engine manufacturers, have been designed in such a way that the data referring to the engine, its components, voyage time, as well as prices of fuel and oil are entered into the data base, and the program provides an overview of all relevant information regarding the recommended timing for changing oil, or a certain part, or an overhaul. The program develops a network which connects components, service and all necessary instructions so that the replacement of worn out parts can be carried out in a successful way (Radica [2], [3]). The program includes the following elements:1) Analysis; 2) Reports; 3) Maintenance; 4) Data transfer; 5) Program description; 6) Support. Data used by the E.I.A. program: 1) Engine data (engine features, model of the engine, power, oil capacity, auxiliary equipment, spare parts and their cost, complete maintenance list, entered into the data base on the basis of experience, codes of all jobs, codes of all components); 2) Information on the user and the data that can be analysed by the user (a number of various kinds of services, changing of the service interval for analysis, changing of spare parts cost, labour description and rates, adding groups of spare parts to the data base, update of the data on preventive maintenance, maintenance of the components, and overhaul intervals, possibility of entering new types of engines, manufactured after the program installation.

\section{Calculation of the load factor in marine propulsion engines}

In order to properly carry out a maintenance analysis of a marine propulsion engine, it is necessary to examine its purpose and application over the assumed life cycle of that engine. The load factor (LF) represents an average requirement in engine operation. It may be defined in two ways: a) through the ultimate fuel consumption; b) by calculating the required working cycle. The load factor LF [\%] can be determined by dividing the actual consumption of fuel [lit], used during a working cycle or voyage, by the amount of fuel which can be used in a specific mode of engine operation during the same period of time (fuel consumption rate $[\mathrm{lit} / \mathrm{h}] \mathrm{X}$ length of working cycle $[\mathrm{h}])$. The fuel mode for a specific voyage is shown in the corresponding specification. This calculation, of course, does not include the time, during a voyage or working cycle, when the engine is not running. Example of the load factor calculation: A ferry driven by two marine engines of $500 \mathrm{KW}$ each uses 132 litres of fuel during a 4-hour 
working cycle. During the cycle the engine is not running for about 40 minutes. This gives the value of the Load factor LF 55 [\%]. The load factor can be determined during the time of the required working cycle, indicating the length of time during which a vessel operates at various engine loads. Example of the load factor calculation: The load factor during the time of the required working cycle for a vessel fitted with two propulsion units may be determined and calculated as follows:1.) Duration of the working cycle - 11 hours; 2.) Running at full speed (100\% power) - 2 hours; 3.) Running at $1500 \mathrm{rev} / \mathrm{min}(55 \%$ power $)$ -6 hours; 4.) When manoeuvring, discharge and loading ( $8 \%$ power $)-2$ hours; 5.) Running with transmission, which is not often used ( $1 \%$ power $)-1$ hour; 6.) Under these conditions the vessel will operate 3500 hours per year. Total calculation gives again 50\% LF.

Full power operation is the period of time during which the engine runs at full speed without changing its working cycle. Except for a continuous operation mode, the time of operation at full load is limited by specific periods of time and recommended engine speed. In order to enable the engine to run in the required operating mode at certain engine speed, the propeller must match the engine as described in the instruction manuals for the specific engine type. If the load factor or the full load time exceeds the allowed limits, guidelines from the instruction manuals should be consulted and the engine switched to the lowest operation mode. Typical operation hours of a vessel / engine in one year are shown in the manual 'Marine Engine Rating Guidelines'. Exceeding the set values will not affect the operation but may result in an increased risk of components failure, reduced engine life and reduced overhaul interval due to the increased operation time.

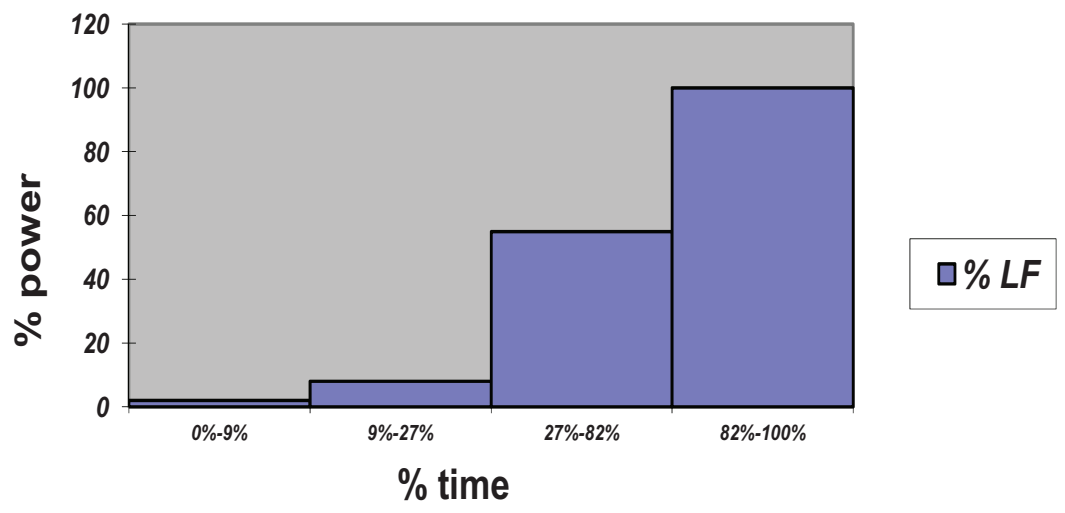

Figure 1: The load cycle according to the calculation.

\subsection{Continuous duty - 'A' operation mode}

This category includes vessels whose engines operate at continuous rating over a long period of time. The constraints involve: 1.) Engine not exceeding the load 
factor limits; 2.) Continuous operation at full power; 3.) Propeller adjusted so that it does not disturb engine operation, i.e. it is not above the engine speed. The typical load factor in this operation mode is $80 \%$ or higher. The load factor calculation for this operation mode (shown in Figure 2).

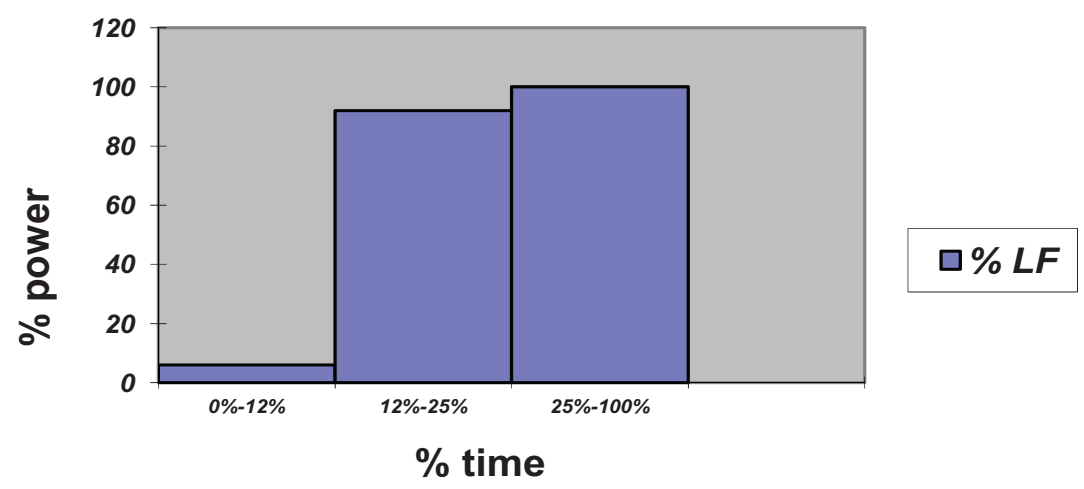

Figure 2: The load cycle according to the calculation for a duty.

\subsection{Heavy duty - 'B' operation mode}

This category includes vessels operating at a constant engine load and constant speed in given cycles. The operating constraints are the following: 1.) Load factor is limited to $80 \%$ or lower; 2.) Full engine rating must be restricted to 10 out of 12 hours of operation; 3.) Propeller adjusted so that it does not disturb engine operation, i.e. it is not above the engine speed. The typical load factor in this operation mode ranges from $40 \%$ to $80 \%$. The load factor calculation for this operation mode (shown in Figure 3).

\subsection{Intermittent duty -' $C$ ' mode}

This category includes vessels operating at variable (intermittent) engine load and at irregular (intermittent) engine speed over specific working cycles. The operating constraints are as follows: 1.)The load factor is limited to $80 \%$ or lower; 2.)Full engine rating must be restricted to 6 out of 12 hours of operation; 3.) Propeller adjusted so that it does not disturb engine operation, i.e. it is not above the engine speed. The typical load factor in this operation mode ranges from $20 \%$ to $80 \%$. The load factor calculation for this operation mode (shown in Figure 4):

The load factor calculation is also one of the features of the E.I.A. program. In addition to diagnostics and analysis of diesel engines, this program controls other systems on board of a vessel as well. 


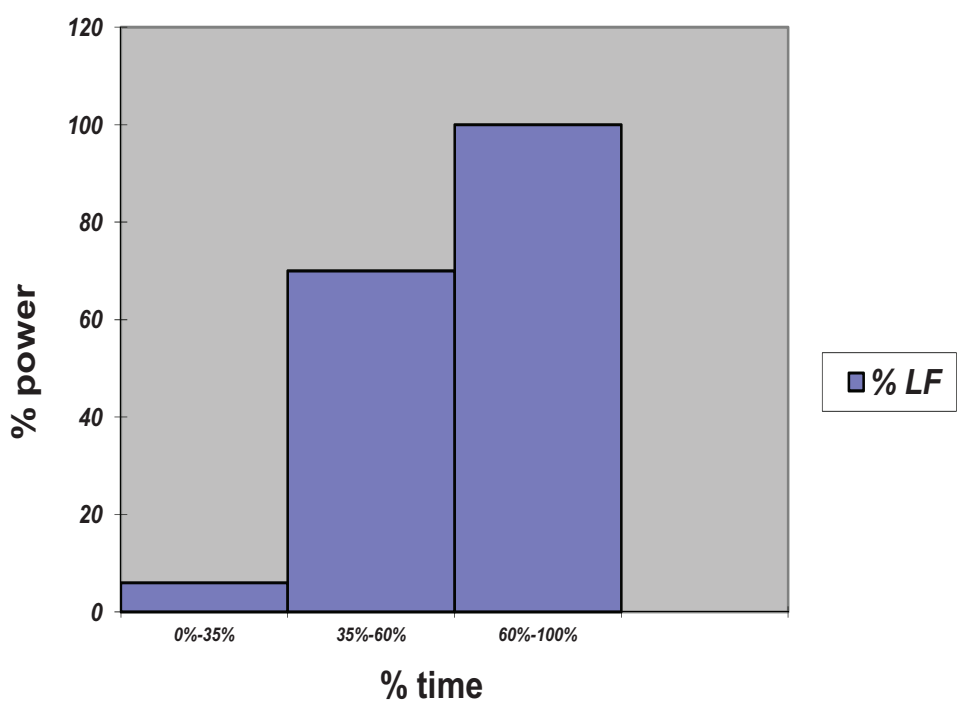

Figure 3: The load cycle according to the calculation for heavy duty.

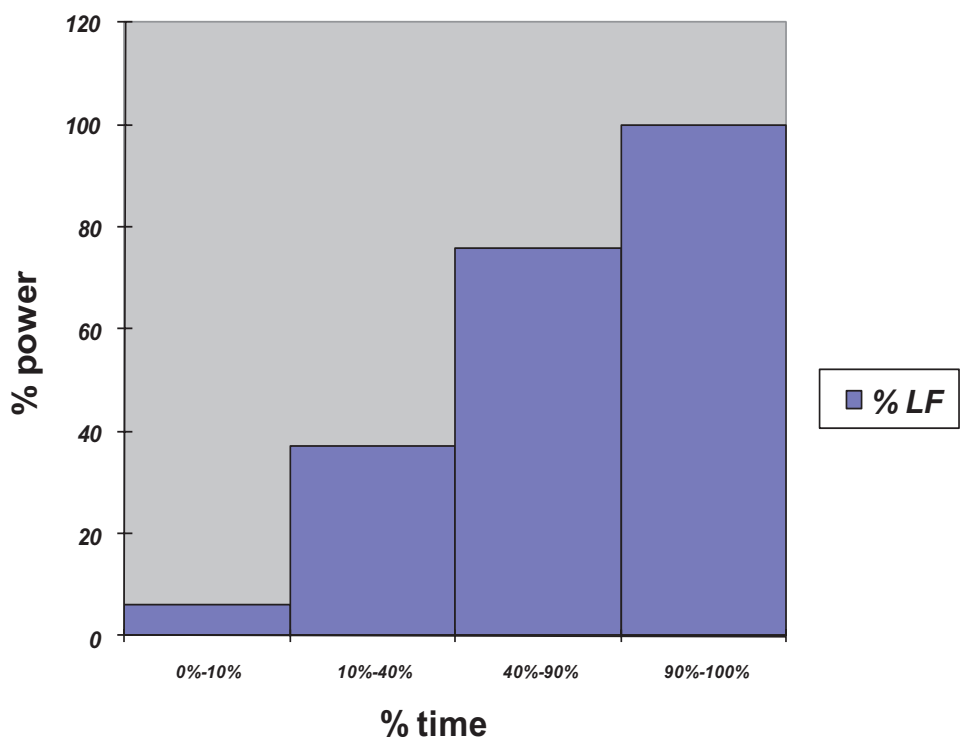

Figure 4: The load cycle for intermittent duty. 


\section{Analysis of marine engine maintenance}

\subsection{Example for yachts}

The following material puts forward an example of the analysis of maintaining, replacing spare parts and overhauling a marine engine with the aid of the 'Engine Investment Analysis' diagnostic system. The engine is a high-speed, four-stroke, twelve-cylinder turbocharged engine having a rated output of $570 \mathrm{KW}$ at 1800 $\mathrm{rev} / \mathrm{min}$, without auxiliaries. In order to process the results, the following parameters have to be entered and calculated: engine type / model, engine power, load factor (according to the calculation made in the previous chapter), selling price of the engine, cost and consumption of diesel fuel and oil (data gathered from the specific engine manual), study time (number of years), yearly operation hours, oil change/spare parts replacements intervals, oil sump size, related auxiliaries. Results of the analysis are: 1) Fuel and oil cost over the study years; 2) Financial summary (selling price, interest, taxes, insurance, fuel cost, oil cost, preventive maintenance, components, overhauls).

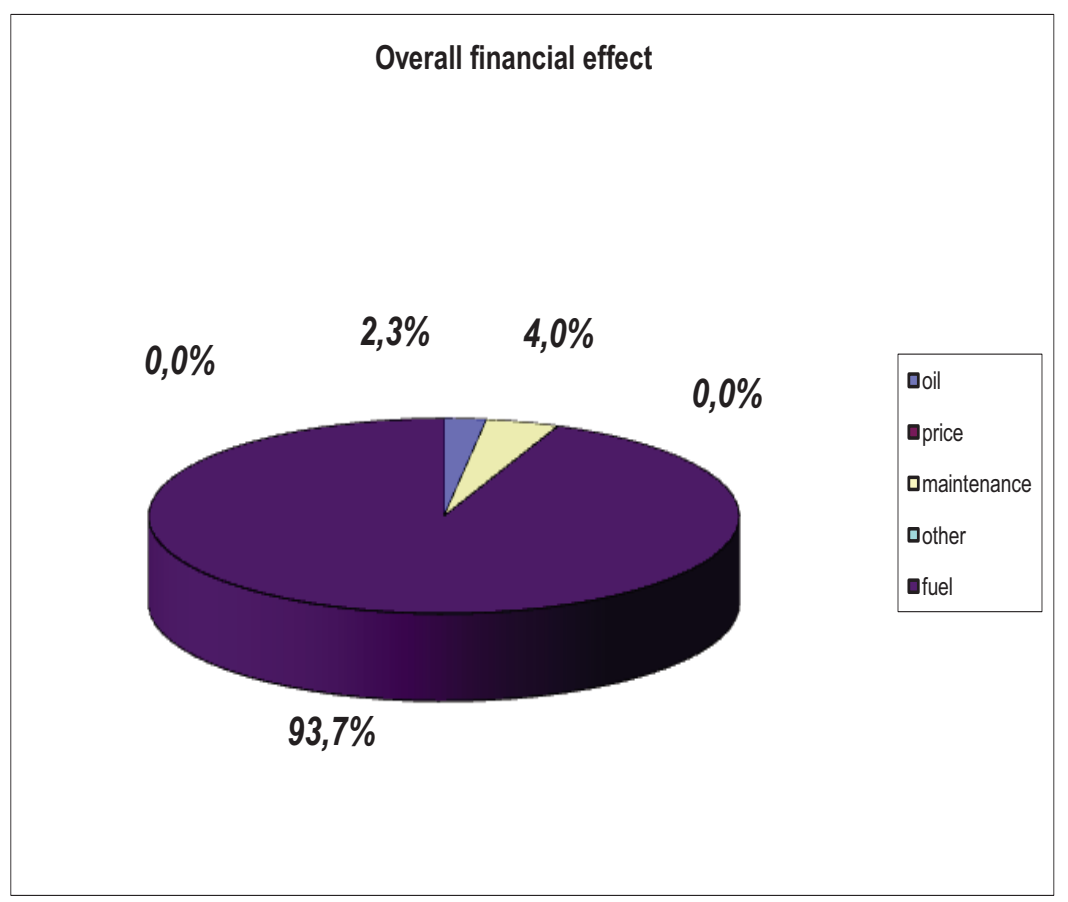

Figure 5: Share of costs of fuel consumption, oil consumption and maintenance. 
The analysis provides a description of all maintenance costs over 15 years. It can be noticed that the largest item participating in these costs is - fuel consumption. This case shows that, over a 15 -year period of engine operation, $93,7 \%$ of all cost refers to fuel; $4 \%$ to maintenance, and $2,3 \%$ to oil change. The values of other costs are negligible.

Engine manufacturers have developed high efficiency engines with technologies able to reduce fuel consumption and to manage fuel injection to fulfil the existing and future IMO emission regulations and to prolong the engine life. Thus the life cost analysis is important from the environmental management point of view.

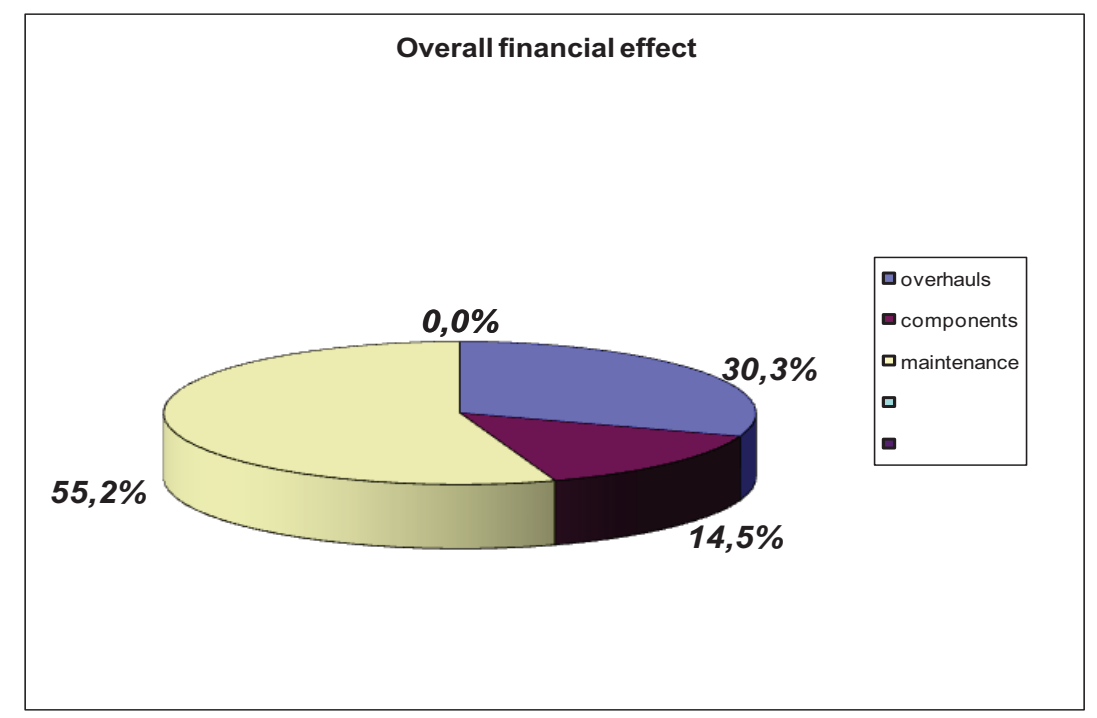

Figure 6: Share of costs of overhaul, spare parts and maintenance.

\section{Conclusion}

This paper presents an economic engine investment analysis over an engine's life cycle. Manufacturers of diesel engines have developed programs for analysing the economic investment effects and overall investment when selecting an engine. A particular attention is paid to maintenance and proper engine operation, leading also to environmental friendly engine. Access to the necessary data is available to enable comparison to other engines. The results of the analysis clearly show the effect of fuel and maintenance as important items that may contribute to a considerable reduction in overall costs. 
610 Ravage of the Planet III

\section{References}

[1] D. Radan: Power/Energy Management of Marine Power Systems, Tech. Report, Department of Marine Technology, NTNU, Trondheim, 2004.

[2] G. Radica: Expert System for Diagnosis and Optimisation of Marine Diesel Engines, Strojarstvo, 2008

[3] G. Radica, R. Antonić, N. Račić.: Engine Working Cycle Analysis for Diagnostic and Optimisation Purposes, Brodogradnja, 2009

[4] V. Tomas, A. Margeta: Next generation control architectures, Pomorstvo, god.20, br. 2, 2006. 